\title{
Does research activity decline with age?
}

\author{
Gylfi Zoega, Professor of Economics, Department of Economics, Univer- \\ sity of Iceland and Department of Mathematics, Economics and Statistics, \\ Birkbeck College, University of London.
}

\begin{abstract}
Several economic models predict that effort may decline as retirement approaches. These models are reviewed and data from the University of Iceland used to measure how research productivity of members of staff depends on age. We find support for the hypothesis that men are at a greater risk of becoming inactive when they approach retirement. Moreover, men tend to be more research active than women in their thirties and forties but lose their edge in their fifties and sixties. Finally, we detect a cohort effect such that later cohorts are more productive than earlier ones.
\end{abstract}

Keywords: Tenure; work effect.

JEL: J14, J22

\section{Introduction}

The term "deadwood" is sometime used in the university context to describe professors or other tenured academics who are no longer effective or useful to their employing institution. ${ }^{1}$ Workers in other professions may also gradually reduce their effort as they get older. Some may also choose to move to professions where opportunities for on-the-job leisure are greater. Thus politicians sometimes end up as diplomats, football players may become celebrities and movie stars may take on fewer roles and end up enjoying leisure and sometimes fame. In some cases the decision is driven by physical deterioration, such as in sports, but in other cases it is less clear why effort would decline with age. ${ }^{2}$

The objective of this paper is to review some of the economic models that predict that effort declines with age and then to use data on research activity at the University of Iceland to test these hypotheses, in particular to test whether research tends to fall with age.

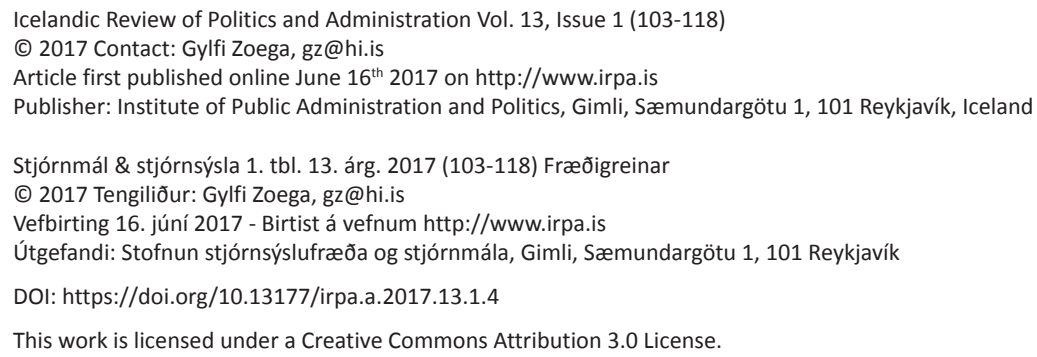




\section{STJÓRNSÝSLA}

\section{Causes of inactivity in late career}

There is empirical evidence showing research productivity to be declining with age. Diamond (1986) uses a longitudinal data set for scientists and mathematicians and finds that the quantity and quality of research output appear to decline continuously with age. Levin and Stephan (1991) use data from the Survey of Doctorate Recipients and the Science Citation Index and find, using longitudinal data, that research activity declined with age in five of the six areas studied. ${ }^{3}$ Goodwin and Sauer (1995) studied the output of academic economists in a sample of 140 tenured professors at seven research oriented universities in the U.S. They found that research output was hump shaped with age so that it initially increased and then declined until retirement. Oster and Hamermesh (1998) find that economists' productivity measured by publications in leading journals declines with age, although the probability of acceptance, once an article has been submitted to a leading journal, is independent of age. ${ }^{4}$ Moreover they find that the median age of authors of articles in leading economics journals was 36 in the 1980s and the 1990s and that a very small minority of authors are over 50 in spite of a substantial proportion of AEA members being over the age of $50 .{ }^{5}$ However, they cannot discriminate between the two possible reasons for this observation; whether the falling frequency of publications is due to deteriorating mental faculties or, alternatively, reflects rational decisions to devote less time to research. In contrast, Jan van Ours (2009) finds no relationship between the quality-adjusted rate of publication and age among his colleagues at Tilburg University.

Reduced research activity among older professors may be caused by them shirking their duties. But they could also have chosen to spend more of their time on administrative duties or the mentoring of younger colleagues. Increased shirking has been discovered in other professions. Figlio (1995), using a multi-year panel data set, found that politicians who have decided to retire from politics often vote against the party line. In this way they shirk their duties as party members. Parker and Powers (2002) found that members of Congress who are about to leave office spend more on foreign travel knowing that they will not be held accountable by voters. In sports, Krautmann and Solow (2009) found that baseball players who are less likely to sign a subsequent contract performed worse, and Cain (2011) found that hockey players' performance worsened as the likelihood of retirement increased.

Standard human capital models can be used to explain why effort may decline with age. Using the Mincer (1958) framework, workers have to choose between working to earn wages and investing in human capital. Academic research has an investment dimension in that current effort yields future publications that the academic adds to his resume and increases his future employability. He may also learn from doing the research and add to his human capital in that way also. Alternatively, he may focus on consulting and teaching, which generates higher current income. In the Ben-Porath (1967) model, we can think of "academic human capital" as having a particularly high depreciation rate a lot of work is required just to keep up to date - and as people get close to retirement they have a smaller incentive to invest in human capital since there are few years left to reap the return from this investment. ${ }^{6}$ Someone close to retirement will clearly have a 
smaller incentive to research and publish in order to get a better job at another university. The empirical prediction of the human capital approach is hence that human capital and research activity may decline with age.

A related reason for why research may fall as retirement approaches is described in Chen and Zoega (2015). Here the consequences of neglecting research are less serious in terms of future career prospects for the older worker because he has fewer remaining years in paid employment left. We use the model of Shapiro and Stiglitz (1984) where workers avoid shirking their duties only out of fear of being dismissed and made unemployed. We show that this threat is less serious for workers approaching retirement and therefore they face a greater incentive to shirk their duties, something that workers like to do in this model if they do not fear dismissal. We will refer to the implications of this and the Ben-Porath effect as the "human capital effect."

There is yet another reason why research productivity may be declining in age, explained in a theoretical model in Chen and Zoega (2011). Research output is partly stochastic in our model - sometimes an editor or a referee likes a paper because he happens to be working on something similar; clearly the choice of referees has a random element; co-authors may work hard or not; and we have family issues that can distract us and so forth. Faced with disappointments, the model predicts that the young may decide to stay research active because they can hope for future successes knowing that they have a long future ahead. Continuing with research in spite of setbacks has an option value in the model since future research may be better received. In contrast, the older professors may think that they are not likely to be lucky in the short remaining span of their tenure and become inactive. Thus, remaining research active allows a professor to hope for future (publication) success, the more years he has left the more time he has to realize these hopes. For this reason old professors may be either very good or inactive while the mediocre younger ones decide to stay research active in the hope of future successes. We refer to this as the "selection effect."

Finally, we can think of a "cohort effect" when an older cohort of academics had more limited opportunities to do research when young due to more limited resources offered by their university and chose to focus more on teaching. A university may also have changed from being a teaching university to becoming a research university. This was the case for the University of Iceland. Research inactive older workers may then only reflect this change of focus. As this cohort ages it appears in a cross section of members of staff that the older workers have reduced their research output while this is not the case.

We will explore data from the University of Iceland to assess the empirical validity of the three hypotheses; the human capital effect, the selection effect, and the cohort effect, first by looking at cross-sectional data and then by looking at panel data.

\section{Research output measured and analysed}

The empirical prediction of the human capital effect is that research activity should be declining in age as the academic approaches retirement and that all university teachers, at least on average, reduce their effort as they approach retirement. The selection effect, 


\section{STJÓRNSÝSLA}

in contrast, has the implication that there are relatively more completely inactive people among the older cohorts while old active academics may be no less active than their younger colleagues. The cohort effect would show up in low activity but not because anyone has reduced his or her research but because the older cohort was never very active because they either did not have the resources from the university to conduct research, were overburdened by teaching or the university was primarily a teaching university during their tenure. The alternative hypothesis would be that people continue research until and perhaps beyond retirement because they enjoy it.

In this section we use data on research output from the University of Iceland (UI) to test the first two predictions while in the following section we explore the implications of the cohort effect. ${ }^{7}$ The university uses data on research activity to calculate a single measure of activity for each member of staff per year. Activities such as publishing papers in academic journals and books, seminar presentations, conference attendance and so forth each give a fixed number of points each that are then summed up to generate one grand total for each member of staff (see appendix). The same point system is used for all departments, which enables us to study research activity for the whole university. We use data for the calendar year 2008 when 640 members of staff were assessed. Tables A1 and A2 in the appendix summarise the data and Figure A1 shows the distribution of output for eight age groups. We should note at the outset that this performance measure is by no means perfect and has important limitations. ${ }^{8}$

In Table 1 we show the number of research inactive member of staff for each age group where research inactivity is defined as having zero points in the UI measure of research activity. We note that this is higher for the oldest three groups than for the younger groups and more than doubles as a proportion of the number of people in each group between the 60-64 and 65-70 years groups. In the 65-70 group we find that 30\% are inactive. Since the point system measures not just the number of articles published in academic journals but also working papers, seminar presentations and so forth, these individuals can be said to be completely inactive when it comes to research.

Table 1. Number of inactive (zero point) members of staff in 2008 by age group

\begin{tabular}{l|rrrrrrrc}
\hline Age & $30-34$ & $35-39$ & $40-44$ & $45-49$ & $50-54$ & $55-59$ & $60-64$ & $65-70$ \\
\hline Inactive & 1 & 5 & 9 & 6 & 14 & 23 & 12 & 18 \\
Total & 20 & 45 & 70 & 91 & 130 & 137 & 88 & 60 \\
\hline$\%$ & 5 & 11.1 & 12.9 & 6.6 & 10.8 & 16.8 & 13.6 & 30 \\
\hline
\end{tabular}

Research inactivity is defined as having zero points in the UI system of measuring research activity. Of the 18 inactive individuals in the oldest group we find that 14 are men (31\% of all men in the age group) and 4 women (26.7\% of all women in the age group).

In Table 2 we present results from the estimation of an equation where output (measured in points in year 2008) is regressed on dummy variables for eight age groups. The objective is to map the age profile of research. Columns (1) and (2) have estimates from least-squares while the Tobit estimator is used in column (3). The Tobit regression is an 
estimation procedure that can accommodate a high probability mass at zero, which is appropriate since one problem encountered is the many zeros in the dependent variable, indicating inactivity. ${ }^{9}$ The coefficients in the table show the number of research points assigned to a member of each age group.

Table 2. Relationship between age, gender and research output in a cross section in 2008 (Least-squares and Tobit estimation)

\begin{tabular}{l|ccc|ccc|ccc|}
\hline & \multicolumn{3}{|c|}{ All } & \multicolumn{3}{c|}{ Men } & \multicolumn{3}{c|}{ Women } \\
\hline & $(1)$ & $(2)$ & $(3)$ & $(4)$ & $(5)$ & $(6)$ & $(7)$ & $(8)$ & $(9)$ \\
\hline age & All & Active & Tobit & All & Active & Tobit & All & Active & Tobit \\
\hline 30-34 & 27.51 & 28.96 & 26.77 & 29.96 & 32.10 & 28.86 & 20.16 & 20.16 & 20.16 \\
& $(5.71)$ & $(5.97)$ & $(5.26)$ & $(4.98)$ & $(5.30)$ & $(4.44)$ & $(3.48)$ & $(3.48)$ & $(3.54)$ \\
35-39 & 26.61 & 30.02 & 24.89 & 30.84 & 37.26 & 27.96 & 18.43 & 18.43 & 18.43 \\
& $(5.82)$ & $(6.13)$ & $(5.07)$ & $(4.65)$ & $(5.06)$ & $(3.82)$ & $(5.71)$ & $(5.70)$ & $(5.81)$ \\
40-44 & 31.52 & 36.17 & 29.70 & 35.96 & 44.68 & 32.89 & 25.25 & 26.15 & 24.89 \\
& $(8.98)$ & $(9.85)$ & $(7.76)$ & $(6.77)$ & $(7.95)$ & $(5.47)$ & $(6.78)$ & $(6.97)$ & $(6.58)$ \\
45-49 & 25.53 & 27.33 & 24.53 & 27.58 & 29.62 & 26.41 & 21.93 & 23.35 & 21.25 \\
& $(10.13)$ & $(10.55)$ & $(9.19)$ & $(8.17)$ & $(8.54)$ & $(7.36)$ & $(6.06)$ & $(6.29)$ & $(5.69)$ \\
50-54 & 26.40 & 29.58 & 24.77 & 28.73 & 32.97 & 26.54 & 23.68 & 25.83 & 22.76 \\
& $(11.56)$ & $(12.35)$ & $(10.01)$ & $(8.42)$ & $(9.13)$ & $(7.06)$ & $(8.02)$ & $(8.44)$ & $(7.45)$ \\
55-59 & 22.99 & 27.67 & 20.38 & 23.80 & 29.19 & 20.60 & 21.30 & 24.68 & 19.72 \\
& $(11.12)$ & $(12.32)$ & $(8.53)$ & $(8.62)$ & $(9.54)$ & $(6.40)$ & $(7.62)$ & $(8.60)$ & $(6.25)$ \\
60-64 & 21.80 & 25.24 & 19.96 & 19.56 & 23.86 & 16.37 & 26.88 & 27.90 & 26.88 \\
& $(9.94)$ & $(10.96)$ & $(7.98)$ & $(7.58)$ & $(8.51)$ & $(5.12)$ & $(6.65)$ & $(6.86)$ & $(6.77)$ \\
65-70 & 18.53 & 26.47 & 13.14 & 18.57 & 26.96 & 12.16 & 18.39 & 25.07 & 42750 \\
& $(6.24)$ & $(7.36)$ & $(3.34)$ & $(5.41)$ & $(6.45)$ & $(2.55)$ & $(3.04)$ & $(3.47)$ & $(2.10)$ \\
R-sq. & 0.02 & 0.02 & - & 0.04 & 0.04 & - & 0.01 & 0.01 & - \\
\hline Obs. & 640 & 552 & 640 & 411 & 342 & 411 & 229 & 210 & 229 \\
\hline
\end{tabular}

The first two columns use OLS (White heteroskedasticity-consistent standard errors and covariance ) to estimate the effect of age while the last one uses Tobit estimation. The numbers in parentheses in columns (1) and (2) are t-statistics while the numbers in parentheses in columns (3) are z-statistics.

The results suggest that research output is rising until the early forties and then declining when both sexes are combined. Men slow significantly down in their fifties and sixties, so much that the average number of points drops from around 36 in their early forties to about 18 in their late sixties or by 50\%. Women also peak in their early forties at around 25 points and decline to 18 in their late sixties. It follows that men tend to produce more than women in their thirties and forties but lose their edge in their fifties and sixties. However, the null hypothesis that research output remains the same throughout life can only be rejected for men at the 5\% level of significance, not for women and not for all 


\section{STJÓRNSÝSLA}

workers groups together. ${ }^{10}$

In the second column we include only the research active. For the whole sample, research activity is now less declining in age - although peaking in the early $40 \mathrm{~s}$ - and for women output in the 65-70 age group exceeds that in the 30-39 age groups. ${ }^{11}$ The equality of coefficients can no longer be rejected for men at the $5 \%$ level of significance although it can still be rejected at the $10 \%$ level. However, the point estimates indicate that output is declining for men so that it peaks at 40-44 as before and falls by close to $40 \%$ in the 65-70 group. This suggests that it is to some extent the research inactive in later working life that pull down average research activity for men in these years although inactivity cannot account for all of the falling output. We should note that the results are robust to the exclusion of any one of the academic departments. Finally, the last column has a (censored) Tobit regression on the whole sample. This gives similar results to the least squares estimation on the whole sample. These results provide support for the selection effect in that leaving out the inactive changes the results.

In Table 3 we redo the estimation of Table 2 but control for academic departments and academic position. All explanatory variables are dummy variables for the age groups, for the academic department and for academic position. ${ }^{12}$

Table 3. Research output, age, academic departments and positions in a cross section in 2008 (least-squares and Tobit estimation)

\begin{tabular}{|c|c|c|c|c|c|}
\hline & & All $(1)^{*}$ & All $(2)^{*}$ & Active (3)* & Tobit $(4)^{* *}$ \\
\hline \multirow{8}{*}{$\begin{array}{l}\text { Age } \\
\text { Group }\end{array}$} & $30-34$ & $30.73(5.14)$ & $36.67(5.94)$ & $36.62(5.92)$ & $38.25(5.87)$ \\
\hline & $35-39$ & $28.65(4.87)$ & $34.81(5.88)$ & $37.68(5.87)$ & $35.62(5.66)$ \\
\hline & $40-44$ & $36.29(6.72)$ & $40.12(7.38)$ & $43.18(7.55)$ & $40.67(7.13)$ \\
\hline & $45-49$ & $29.95(6.69)$ & $30.71(6.86)$ & $32.06(6.79)$ & $30.92(6.70)$ \\
\hline & $50-54$ & $30.89(6.02)$ & $30.48(5.86)$ & $32.99(5.96)$ & $29.99(5.61)$ \\
\hline & $55-59$ & $28.13(6.42)$ & $25.05(5.65)$ & $29.45(6.22)$ & $23.08(4.93)$ \\
\hline & $60-64$ & $26.03(5.44)$ & $22.19(4.46)$ & $24.31(4.51)$ & $20.62(3.99)$ \\
\hline & $65-70$ & $22.03(4.80)$ & $19.19(4.20)$ & $24.79(4.87)$ & $14.01(2.79)$ \\
\hline \multirow{12}{*}{$\begin{array}{l}\text { Academic } \\
\text { Departments }\end{array}$} & Social and human sciences & $8.73(1.56)$ & $0.94(0.12)$ & $-1.31(0.17)$ & $1.21(0.15)$ \\
\hline & Social work & $-6.89(0.93)$ & $-7.31(0.88)$ & $-12.11(1.37)$ & $-5.31(0.63)$ \\
\hline & Economics & $3.84(0.42)$ & $-2.33(0.28)$ & $1.86(0.21)$ & $-4.35(0.48)$ \\
\hline & Law & $-2.89(0.44)$ & $-8.34(1.07)$ & $-7.46(0.89)$ & $-10.19(1.20)$ \\
\hline & Political science & 10.73 (1.09) & $-2.32(0.20)$ & $-6.32(0.52)$ & $-2.71(0.23)$ \\
\hline & Business Administration & $-16.94(3.26)$ & $-19.47(2.63)$ & $-24.33(2.95)$ & $-21.48(2.69)$ \\
\hline & Nursing & $-11.66(1.96)$ & $-14.90(1.97)$ & $-16.42(2.04)$ & $-15.31(1.89)$ \\
\hline & Pharmaceutical sciences & $-9.95(1.19)$ & $-22.27(2.32)$ & $-25.01(2.59)$ & $-22.99(2.34)$ \\
\hline & Medicine & $-11.60(2.46)$ & $-16.63(2.50)$ & $-16.64(2.34)$ & $-19.42(2.73)$ \\
\hline & Food science and nutrition & $7.85(0.63)$ & $1.77(0.16)$ & $-2.32(0.20)$ & $2.59(0.23)$ \\
\hline & Psychology & $3.67(0.37)$ & $-2.12(0.20)$ & $-6.41(0.59)$ & $-1.24(0.12)$ \\
\hline & Odontology & $-12.11(1.35)$ & $-11.33(1.16)$ & $-7.91(0.58)$ & $-16.80(1.46)$ \\
\hline
\end{tabular}




\section{STJÓRNSÝSLA}

\begin{tabular}{l|l|c|c|c|c|} 
& Languages, literature and linguistics & $-13.21(2.37)$ & $-16.13(2.13)$ & $-17.00(2.11)$ & $-17.48(2.06)$ \\
& Theology and religious studies & $-11.93(1.72)$ & $-18.18(2.14)$ & $-20.50(2.20)$ & $-20.69(2.11)$ \\
& Icelandic and comparative cultural st. & $2.83(0.40)$ & $-4.18(0.48)$ & $-8.47(0.94)$ & $-3.13(0.35)$ \\
& History and philosophy & $10.09(1.49)$ & $0.90(0.12)$ & $-3.05(0.39)$ & $1.46(0.19)$ \\
& Sport, leisure st. and social education & $-9.89(1.44)$ & $-9.78(1.22)$ & $-11.93(1.47)$ & $-9.02(1.04)$ \\
& Teacher education & $-7.66(1.57)$ & $-5.52(0.78)$ & $-9.91(1.29)$ & $-3.68(0.49)$ \\
& Educational studies & $2.21(0.32)$ & $-2.63(0.32)$ & $-6.29(0.73)$ & $-1.20(0.14)$ \\
& Industrial-, mech. eng. and comp.s. & $-9.46(1.66)$ & $-20.74(2.65)$ & $-18.61(2.22)$ & $-24.04(2.76)$ \\
& Earth sciences & $11.05(1.74)$ & $-3.69(0.46)$ & $-8.69(1.01)$ & $-2.34(0.29)$ \\
& Life and environmental sciences & $-2.59(0.49)$ & $-0.60(0.07)$ & $-14.24(1.91)$ & $-11.78(1.57)$ \\
& Electrical and computer engineering & $3.20(0.29)$ & $-5.00(0.45)$ & $-3.39(0.27)$ & $-7.73(0.65)$ \\
\hline Position & Physical sciences & $-7.15(1.29)$ & $-18.74(2.64)$ & $-16.62(2.12)$ & $-22.71(2.93)$ \\
& Civil and environmental engineering & $8.74(1.03)$ & $-11.39(1.61)$ & $-1.93(0.22)$ & $-1.41(0.16)$ \\
\hline \multirow{2}{*}{ Observations } & Professor & & $16.98(3.26)$ & $17.88(3.29)$ & $18.69(3.34)$ \\
\hline & Associate professor & & $3.62(0.72)$ & $4.43(0.84)$ & $3.29(0.60)$ \\
& Assistant professor & & $-5.78(1.13)$ & $-2.49(0.46)$ & $-8.92(1.58)$ \\
\hline
\end{tabular}

*) OLS estimates, White heteroskedasticity-consistent standard errors and covariance, t-statistics in parentheses. **) z-statistics in parentheses.

We find the same age pattern of research as in Table 2. In addition, we find that business administration was weak in 2008, as well as several other departments such as nursing, pharmaceutical sciences, medicine, languages and theology. In contrast, political science, history and philosophy, earth sciences and civil and environmental engineering did better on average. It should be noted that this pattern may only reflect research output in the year 2008 since average output at the departmental level may fluctuate from one year to another due to the small size of departments. In column (2), we also test for an effect of academic titles since professors may reduce their research output because they can hope for no further promotions while low output cannot put their status in jeopardy. We find that professors at the University of Iceland have almost 17 points more on average than other members of staff. In column (3) we only include the research active and find, as before, that the slowdown in output in later years is still present.

We finally run a logit regression on the binary variable for inactivity (inactivity gives the value one to the variable, otherwise zero), which we explain with age, gender and dummy variables for professors, associate professors and assistant professors. The results for a logit (binary) pooled cross-section, time-series regression for the years 20032009 are shown in Table 4. 
Table 4. Logit estimation of the effect of age, sex and position on inactivity using a pooled cross-section time-series regression 2003-2009

\begin{tabular}{lcc}
\hline & \multicolumn{2}{c}{ All } \\
\hline Age & estimate & z-statistic \\
\hline Constant & 0.27 & 0.84 \\
D-male & -1.87 & 4.61 \\
Age & -0.03 & 4.27 \\
D-male*age & 0.05 & 5.75 \\
Professor & -1.92 & 15.31 \\
Assoc. professor & -0.76 & 7.21 \\
Assist. professor & -0.21 & 2.10 \\
\hline R-squared (McFadden) & \multicolumn{2}{c}{0.08} \\
\hline Observations & \multicolumn{2}{c}{4942} \\
\hline
\end{tabular}

The dependent variable takes the value 1 if an individual has no measured research activity (zero points) and 0 otherwise. Maximum-likelihood estimation: Logit.

From the coefficient estimates for age and gender we find men below the age of 38 are less likely to be inactive than women, but more likely to be inactive than women above that age. In contrast, women are less likely to become inactive with age. Assistant professors and associate are also more likely to be inactive than professors. ${ }^{13}$ The results suggest that it is age and gender, not status or job security, which affects the probability that someone becomes research inactive.

However, we should note that the explanatory power of the equations is limited (R-squared no higher than 0.08), which implies that other factors than age are important for the research activity of each individual. This leads us to the main weakness of the estimation which is that some of the omitted variables may be correlated with age. Moreover, the cohort effect may be explaining the inactivity among the older workers, reflecting the change in the university from being primarily a teaching university to becoming a research university. In order to address this problem we perform panel estimation in the following section.

\section{Cohort effects and individual heterogeneity}

The regression analysis in the previous section suffers from the limitation that the ageproductivity relationship may be caused by individual-specific unmeasurable heterogeneity and also cohort effects. In particular, the older academics may be less active because they belong to a different cohort that may not have had the resources, opportunities or pressure to develop their research potential due to changed university policies. In order to control for this the panel regression - a pooled cross-section, time-series analysis with random effects reported in Table 5 was performed using data on research output for 719 individuals in the seven years from 2003 to 2009. Here individual research activity is followed through the period 2003-2009. 
The first column of Table 5 reports the results when all members of staff are included. The regressors include the age of each individual, his rank and academic department (results not shown but used as controls). A dummy variable for gender (male =1) and an interaction term for this dummy variable and age is added in column (2). In column (3) there are cohort effects through the interaction of age and a dummy variable for year 2003 and a dummy for year 2009. The cohort effects test whether someone at a given age in 2003 was more or less productive than someone at the same age in 2009. Research inactive individuals are omitted in column (4).

Table 5. Relationship between research output, age and cohort using a pooled cross-section time-series regression 2003-2009 (cross-section random effects)

\begin{tabular}{lcccc}
\hline Variable & All & All & All & Active \\
\hline \multirow{2}{*}{ Constant } & $(1)$ & $(2)$ & $(3)$ & $(4)$ \\
Age & -19.33 & 8.53 & 12.53 & 22.57 \\
& $(5.77)$ & $(1.73)$ & $(2.48)$ & $(0.78)$ \\
D-male & -0.19 & 0.04 & -0.04 & -0.17 \\
& $(2.88)$ & $(0.42)$ & $(0.43)$ & $(1.50)$ \\
D-male*Age & & 17.29 & 17.03 & 13.66 \\
& & $(2.92)$ & $(2.87)$ & $(2.11)$ \\
d03*age & & -0.37 & -0.36 & -0.27 \\
& & $(3.10)$ & $(3.04)$ & $(2.10)$ \\
d09*age & & & -0.07 & -0.08 \\
& & & $(5.23)$ & $(4.73)$ \\
Professor & & & -0.01 & -0.01 \\
& & & $(0.86)$ & $(0.42)$ \\
Associate professor & 29.69 & 29.58 & 30.56 & 27.75 \\
& $(13.44)$ & $(13.29)$ & $(13.65)$ & $(11.59)$ \\
Assistant professor & 14.04 & 13.72 & 14.18 & 12.01 \\
& $(6.36)$ & $(6.20)$ & $(6.40)$ & $(5.07)$ \\
\hline Observations & 5.40 & 5.35 & 5.63 & 4.42 \\
\hline R-squared & $(2.46)$ & $(2.44)$ & $(2.57)$ & $(1.86)$ \\
\hline F-statistic & 4941 & 4941 & 4941 & 4071 \\
\hline
\end{tabular}

Random effects estimator: Swamy and Arora estimator of component variances. t-statistics in parentheses * indicates significance at the $5 \%$ level. Departmental controls were included.

The results in column (1) are consistent with the cross-section results in that the coefficient of age is statistically significant and negative. In column (2) we find that the coefficient of the dummy variable for men is statistically significant but their research output 
declines more rapidly, consistent with our earlier results. Cohort effects are added in column (3), which reveal that individuals of all ages were less productive in 2003 than in 2009. This implies that cohort effects explain part of our earlier results about the lower productivity of the older generation at a given point in time. However, the age variable is still significant for males even when the cohort variables are included. Finally, the results in column (4) where research inactive individuals have been dropped are qualitatively the same as when they are included in column (3). Consistent with earlier results the productivity of males declines less rapidly when the inactive are excluded but they nevertheless decline with age. We thus find support for all three effects; the human capital effect (research of the active members of staff is declining in age), the selection effect (inactivity is increasing in age), and the cohort effect (older cohorts less productive).

\section{Conclusions}

Measured research output may decline as an academic approaches retirement for several reasons. First, the future rewards from successful research and the penalty from having not engaged in research decrease with fewer years remaining in the profession. Second, setbacks in publishing may affect the older academics more because the younger ones have more years ahead to expect successes. Third, any apparent relationship between age and research activity may only reflect a cohort effect, the older cohort not having had the same opportunities for research during their tenure.

Looking at data on research output from the University of Iceland, we find support for all three effects: The risk of becoming inactive is rising in age for men, the output of research active men tends to fall in age; and the older cohorts are less productive than the most recent ones. These results are consistent with those of Oster and Hamermesh (1998) who also found that research activity was declining in age. As in Levin and Stephan (1991) we find that publishing productivity reaches a peak in the early to midforties. The increased job security of professors does not reduce research; professors tend to be considerably more productive than either associate professors or assistant professors. There are also significant differences between average research outputs between departments.

There are interesting differences between the genders. Men slow significantly down in their fifties and sixties after peaking in their early forties; the measured output drops by $50 \%$ from the early forties to their late sixties. Women also peak in their early forties but drop by $28 \%$ from their early forties to their late sixties. Men tend to produce more than women in their thirties and forties but lose their edge in their fifties and sixties. When only the research active are included, research activity is now less declining in age for men and especially for women. This suggests that it is to some extent the research inactive in later working life that pull down average research activity in these years. One possible reason for the gender differences is that motherhood affects the research of women adversely in their thirties and forties. ${ }^{14}$ However, the university data on research activity do not allow us to test for this effect. Further work is needed to explore the reasons for the different age pattern of research of men and women academics at the 
university. This would involve using survey data that matched personal attributes and family status with the research output.

The results provide support for the selection and the cohort effects. Panel estimation, which includes individual-specific random effects and also terms that correct for cohort differences show that older cohorts are less productive while not changing the result that research output is falling in age. Thus, we find that the output of research active men falls with age and their rate of inactivity increases while older cohorts are less productive.

Finally, a note on the limitations of this study. Assigning one number to measure the research output of an academic clearly provides only a very rough measure of his research activity, as explained in footnote 8 . Someone spending years writing a book or a paper that subsequently gets published in a top journal or by a good publisher would be assigned a lower measure of output than someone publishing several papers in a lesser journal or by a lesser publishing house in the system used at the University of Iceland. Thus any numerical measure of research output is fundamentally subjective. Having said that, to the extent that members of staff respond to the incentives of their own home institution, the measure of performance can be used in this study.

\section{Notes}

1 See http://medical-dictionary.thefreedictionary.com/deadwood.

2 Even in the case of athletes, the retirement decision is to some extent up to the individual's discretion because the rate of deterioration of physical ability has been shown to be quite small. See Fair (1994, 2007) who fails to find a strong effect of aging on physical abilities.

3 Only in particle physics was there no age effect present.

4 They include both single-author and multi-author publications.

5 Similar results are reached by Lehman (1953and for other disciplines.

6 McDowell (1982) calculates depreciation rates for different academic fields and finds that it varies so that it is lower in humanities. He argues that this may explain why women are overrepresented in humanities and underrepresented in the sciences due to expected disruptions in their careers due to motherhood.

7 The data were provided by Baldvin Zarioh in the Division of Science and Innovation at the University of Iceland.

8 The research points mix magnitude and quality of research. Thus a paper published in a refereed international journal gives more points than a possibly more labour-intensive paper published in a domestic journal. Also, publishing a greater number of smaller, less labour-intensive papers may generate more points than publishing fewer more labour-intensive papers. The rule used to take into account the number of co-authors is also rather ad-hoc and can be criticized, i.e. the lead author gets the same number of points as the less decisive co-author. There were also some changes in the system during the period 2003-2008 so that the years are not entirely comparable.

9 The Tobit model is designed to estimate linear relationships between variables when there is either left- or right-censoring in the dependent variable. In this case there is censoring from below at zero points.

10 A Wald test for the equality of all age coefficients yields $\mathrm{F}=1.64$ (probability $=0.12$ ) for all members of staff; $F=2.21$ (probability of 0.03 ) for men; and $F=0.61$ (probability of 0.75 ) for women. Hence, only in the case of men is the equality rejected.

11 The Wald test for the equality of all coefficients yields $F=1.04$ (probability $=0.40$ ) for all members 


\section{STJÓRNSÝSLA}

of staff; $\mathrm{F}=1.99$ (probability of 0.06 ) for men; and $\mathrm{F}=0.73$ (probability of 0.64 ) for women. We can reject equality for men at the $10 \%$ level of significance but we cannot reject equality in the case of women nor the whole sample.

12 Thus from column (2) we can see that a 55-59 year old member of the economics department who is a professor would have $25.05-2.33+16.98=39.7$ research points.

13 We should note that the age profile is similar for the three academic positions; the average age of professors in the sample was 56, the average age of associate professors 52 and the average age of assistant professors was 49 .

14 This was the finding of Zie and Shauman (1998) and Shauman and Xie (1996).

\section{References}

Ben-Porath, Y. (1967). "The Production of Human Capital and the Life Cycle of Earnings", The Journal of Political Economy 75 (4), Part 1, 352-365.

Cain, L.D. (2011). "Shirking in the National Hockey League", Manuscript, Union College, New York.

Chen, Y. and Gylfi Zoega (2015). "A Non-perpetual Shirking Model”, Economics Letters 134, 98-101.

Chen, Y. and Gylfi Zoega (2011). "Life-Cycle, Effort and Academic Deadwood", University of Dundee Discussion Paper DP-2011-27.

Diamond, A. (1986). "The Life-Cycle Research Productivity of Mathematicians and Scientists", Journal of Gerontology 41, 520-525.

Fair, R.C. (1994). "How Fast Do Old Men Slow Down?”, The Review of Economics and Statistics 76 (1), 103-118.

Fair, R.C. (2007). "Estimated Age Effects in Athletic Events and Chess", Experimental Aging Research 33 (1), 37-57.

Figlio, D.N. (1995). “The Effect of Retirement On Political Shirking: Evidence From Congressional Voting", Public Finance Review 23 (2), 226-241.

Frank, R. (1984). "Are workers paid their marginal products?", The American Economic Review 74 (4), 549-571.

Goodwin, T.H. and Sauer, R.D. (1995). "Life Cycle Productivity in Academic Research: Evidence from Cumulative Publication Histories of Academic Economists", Southern Economic Journal 61 (3), 728-743.

Krautmann, A.C. and Solow, J.L. (2009). "The Dynamics of Performance Over the Duration of Major League Baseball Long-Term Contracts", Journal of Sports Economics 10 (1), 6-22.

Lehman, Harvey (1953). Age and Achievement. Princeton: Princeton University Press.

Levin, S.G. and Stephan, P.E. (1991). "Research Productivity Over the Life Cycle: Evidence for Academic Scientists", The American Economic Review 81 (1), 114-132.

McDowell, J. (1982). "Obsolescence of Knowledge and Career Publication Profiles", American Economic Review 72, 752-768.

Mincer, J. (1958). "Investment in Human Capital and Personal Income Distribution", The Journal of Political Economy 66 (4), 281-302.

Mincer, J. and Ofek, H. (1982). "Interrupted Work Careers: Depreciation and Restoration of Human Capital", The Journal of Human Resources 17 (1), 3-24.

Oster, S.M. and Hamermesh, D.S. (1998). "Aging and Productivity Among Economists", The Review of Economics and Statistics 80 (1), 154-156.

Parker, G.R. and Powers, S.C. (2002). "Searching for Symptoms of Political Shirking: Congressional Foreign Travel”, Public Choice 110 (1), 173-191.

Shauman, K.A. (1996). "Geographic Mobility of Scientists: Sex Differences and Family Constraints", Demography 33 (4), 455-468.

Van Ours, J.C. (2010). “Will you still need me - when I'm 64?”, unpublished version of van Ours' Presidential Address at the European Society for Population Economics annual conference in Seville, June 12, 2009. 
Xie, Y. and Shauman, K.A. (1998). "Sex Differences in Research Productivity: New Evidence about an Old Puzzle”, American Sociological Review 63 (6), 847-870.

\section{Appendix}

University of Iceland point system for research (Since 2003)

\section{A1. Dissertations}

A1.1 Candidate- or masters thesis (15 points)

A1.2 Doctoral thesis (30 points)

\section{A2. Books}

A2.1 Books, academic (10-60 points)

A2.2 Books, republications (0-10 points)

\section{A3. Academic articles in journals}

A3.1 Article in internationally acknowledged journals cited in ISI Web of Science(15 points)

A3.2 Article in other refereed journals (10 points)

A3.3 Other material in refereed journals ( $0-5$ points)

A3.4 Article in a non-refereed journal ( $0-5$ points)

A4. Papers in refereed conference proceedings and book chapters

A4.1 Paper in a refereed conference proceedings (5-10 points)

A4.2 Book chapter (5-10 points)

A5. Other academic activity

A5.1 Scientific report or memorandum (0-5 points)

A5.2 Book review (1-2 points)

A5.3 Lectures

5.3.1 Lecture at scientific conference (3 points)

5.3.2 Lecture for the academic community (1 point)

5.3.3 Plenary lecture or keynote address at an international conference ( 5 points)

A5.4 Posters

5.4.1 Poster at a scientific conference ( 2 points)

5.4.2 Poster at other meetings (1 point)

A5.5 Translations ( $0-10$ points)

A5.6 Other (software, patents, psychological tests, bills, design projects etc.) (0-10 points)

\section{A6. Citations in ISI Web of Science}

First 10 citations: 1 point/citation

Next 20 citations: 0,5 point/citation

Citations exceeding 30: 0,1 point/citation.

\section{Editorial work, academic publications}

7.1. Editor of an academic journal (2-5 points/year)

7.2. Member of editorial board of an academic journal (1-2 points/year)

7.3. Editor of an academic book (2-5 points)

7.4 Member of editorial board of an academic book (1-2 points)

In the case of multiple author articles or books, the points are calculated using the following formula: 2 authors: $1,5 \mathrm{x}$ points / 2, 3 authors: $1,8 \mathrm{x}$ points / 3, 4 authors or more $2,0 \mathrm{x}$ points / number of authors 


\section{STJÓRNSÝSLA}

Table A1. Summary of data - Departments

\begin{tabular}{|c|c|c|c|c|c|c|c|}
\hline Schools & Departments & $\begin{array}{c}\text { Staff } \\
\text { members }\end{array}$ & Men & Women & $\begin{array}{l}\text { Average } \\
\text { age }\end{array}$ & $\begin{array}{l}\text { Research } \\
\text { output - } \\
\text { average } \\
\text { points - }\end{array}$ & $\begin{array}{l}\text { Research } \\
\text { output - } \\
\text { standard } \\
\text { deviation }\end{array}$ \\
\hline \multirow{6}{*}{ Social sciences } & Social and human sciences & 22 & 10 & 12 & 51.7 & 38.6 & 17.0 \\
\hline & Social work & 7 & 1 & 6 & 51.0 & 24.2 & 15.4 \\
\hline & Economics & 15 & 14 & 1 & 45.8 & 33.6 & 31.6 \\
\hline & Law & 25 & 17 & 8 & 46.1 & 27.7 & 26.0 \\
\hline & Political science & 7 & 7 & 0 & 50.1 & 40.6 & 25.1 \\
\hline & Business Administration & 18 & 15 & 3 & 50.7 & 13.1 & 13.2 \\
\hline \multirow[t]{6}{*}{ Health sciences } & Nursing & 29 & 3 & 26 & 50.7 & 18.6 & 21.8 \\
\hline & Pharmaceutical sciences & 9 & 4 & 5 & 46.4 & 19.6 & 21.7 \\
\hline & Medicine & 110 & 77 & 23 & 54.8 & 17.1 & 22.9 \\
\hline & Food science and nutrition & 9 & 6 & 3 & 51.6 & 36.7 & 36.9 \\
\hline & Psychology & 11 & 9 & 2 & 50.7 & 33.4 & 30.3 \\
\hline & Odontology & 17 & 15 & 2 & 54.6 & 16.6 & 34.3 \\
\hline \multirow{4}{*}{ Humanities } & Languages, literature and linguistics & 19 & 8 & 11 & 50.7 & 16.7 & 16.4 \\
\hline & Theology and religious studies & 10 & 8 & 2 & 54.4 & 18.4 & 16.8 \\
\hline & $\begin{array}{l}\text { Icelandic and comparative cultural } \\
\text { studies }\end{array}$ & 29 & 15 & 14 & 52.7 & 31.9 & 30.7 \\
\hline & History and philosophy & 26 & 20 & 6 & 53.5 & 39.3 & 25.7 \\
\hline \multirow{3}{*}{ Education } & $\begin{array}{l}\text { Sport, leisure studies and social } \\
\text { education }\end{array}$ & 11 & 5 & 6 & 47.1 & 21.0 & 17.3 \\
\hline & Teacher education & 70 & 28 & 42 & 56.3 & 20.4 & 20.4 \\
\hline & Educational studies & 25 & 18 & 7 & 54.9 & 30.2 & 26.8 \\
\hline \multirow{6}{*}{$\begin{array}{l}\text { Engineering and } \\
\text { Natural Sciences }\end{array}$} & $\begin{array}{l}\text { Industrial-, mechanical engineering } \\
\text { and computer science }\end{array}$ & 21 & 19 & 2 & 49.0 & 21.1 & 18.8 \\
\hline & Earth sciences & 8 & 7 & 1 & 60.3 & 36.4 & 17.3 \\
\hline & Life and environmental sciences & 31 & 17 & 14 & 51.3 & 27.1 & 18.3 \\
\hline & Electrical and computer engineering & 10 & 9 & 1 & 49.2 & 33.6 & 34.1 \\
\hline & Physical sciences & 42 & 41 & 1 & 53.5 & 20.6 & 26.2 \\
\hline & Civil and environmental engineering & 15 & 14 & 1 & 51.6 & 37.4 & 28.1 \\
\hline
\end{tabular}

The table shows the number of members of staff, their average age, average number of research points and the within-group standard deviation.

Table A2. Summary of data - Institutes

\begin{tabular}{l|ccc|c|c|c}
\hline Institutes & All staff & Men & Women & $\begin{array}{c}\text { Average } \\
\text { age }\end{array}$ & $\begin{array}{c}\text { Research } \\
\text { output - } \\
\text { average points }\end{array}$ & $\begin{array}{c}\text { Research output } \\
- \text { standard } \\
\text { deviation - }\end{array}$ \\
\hline The Árni Magnússon Institute for Icelandic Studies & 14 & 10 & 4 & 57.6 & 29.4 & 21.3 \\
\hline Institute for Experimental Pathology, University of Iceland & 10 & 3 & 7 & 57.7 & 18.7 & 13.1 \\
\hline Science Institute & 26 & 19 & 7 & 49.2 & 34.4 & 36.8 \\
\hline Other institutes & 4 & 4 & 0 & 43.5 & 11.7 & 4.4 \\
\hline
\end{tabular}

The table shows the number of members of staff, their average age, average number of research points and the within-group standard deviation. 
Figure A1. The distribution of output for different age groups
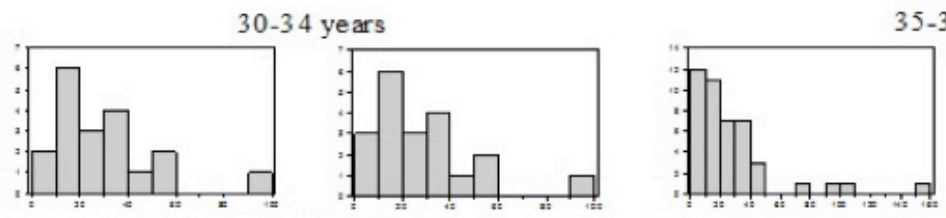

35-39 years
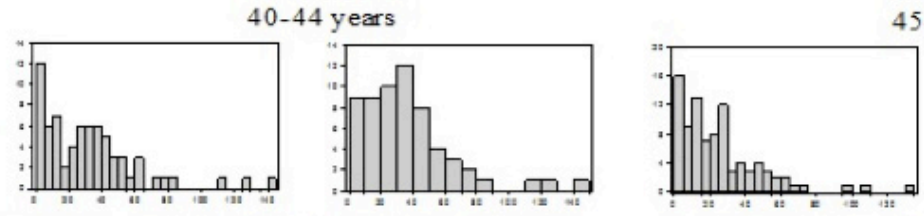

45-49 years
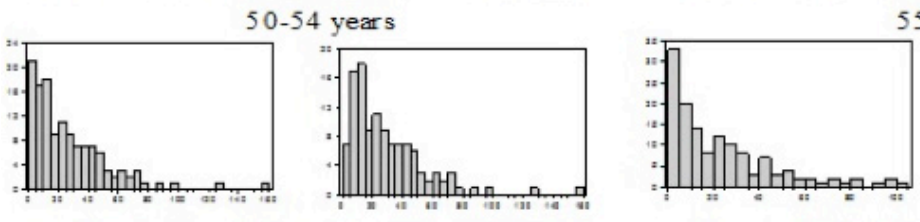

55-59 years

60-64 years
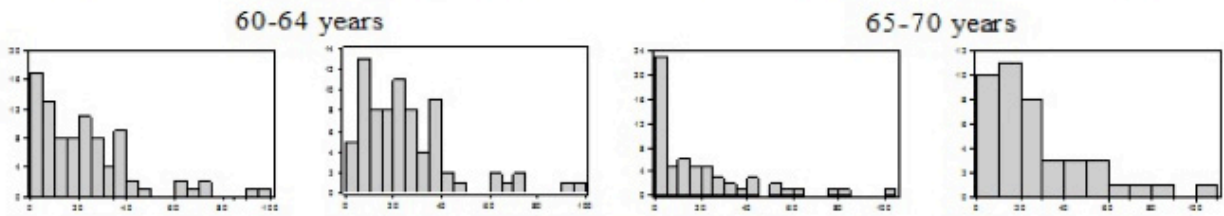

The left-hand panel shows the distribution of research output when everyone is included while the right-hand side panel show the distribution when the research inactive have been removed from the sample. 
